\title{
Marital Surname Change and Marital Duration Among Divorcées in a Canadian County
}

\author{
Melanie MacEacheron* \\ Department of Psychology, University of Western Ontario, London, ON, Canada
}

Women's marital surname change has been discussed as comprising one possible signal of intention to remain married, and may be perceived as such, and valued, by husbands. Here, the practice was investigated as a potential predictor of marital duration among couples who went on to divorce. An archival analysis was based on a search of all available, opposite-sex divorces filed over an 8-month period in a Canadian county. Among couples $(n=107)$ divorcing, marriages the women in which underwent marital surname change lasted $60 \%$ longer, controlling for wife's age at the time of marriage. When the woman's marital surname change/retention was used as a regression predictor of number of children of the marriage alongside marriage duration in years, only the latter was predictive. No husband took his wife's surname. Giving the maternal surname (along with the paternal surname) to children occurred at a negligible frequency. Potential reasons for these findings including costly signaling and, ultimately, paternity uncertainty, as well as possible implications for public policy, are discussed.

Reviewed by:

Gary L. Brase,

Kansas State University, United States

Bruna Nascimento, Brunel University London, United Kingdom

*Correspondence: Melanie MacEacheron mmaceacheron@gmail.com

Specialty section:

This article was submitted to Evolutionary Psychology, a section of the journal

Frontiers in Psychology

Received: 30 December 2020 Accepted: 19 April 2021 Published: 16 June 2021

Citation:

MacEacheron M (2021) Marital

Surname Change and Marital Duration Among Divorcées in a Canadian County.

Front. Psychol. 12:647942. doi: 10.3389/fpsyg.2021.647942

\section{INTRODUCTION}

In countries such as Canada and the US, women, and only women, customarily change surname at marriage to that of their male spouses despite surname retention being the default and easier option. In fact, only 6\% (Gooding and Kreider, 2010) or 4.6\% (Johnson and Scheuble, 1995) of US women may choose non-traditional marital surnaming (analogous data unavailable for Canada). Reasons for the custom may include such change comprising one, possible, costly signal of marital commitment, which is on average desired by men (MacEacheron, 2016a, 2020: regarding costly signaling generally, see Nesse, 2001). Yet some married women continue to use their premarital surnames. There is evidence that men care whether their wives take their surname (for instance, possessing this as an expectation: Lockwood et al., 2011), as well as, perhaps, whether their children are surnamed for them (e.g., Cherlin, 1978: see also Robnett and Leaper, 2013). Marital surname choice is reported to sometimes be a fraught decision (e.g., Boxer and Gritsenko, 2005).

Marital surname choice has been reported as seen by women as potentially negatively impacting women's earnings (Goldin and Shim, 2004). Yet, it has been viewed as particularly appropriate for couples planning children (Scheuble and Johnson, 1998) - an expensive enterprise. There is also evidence of largely negative perceptions of women based on their retention or hyphenation of premarital surnames. Such perceptions include that they possess 
attributes and behavior that may lead to divorce or poorer mothering (e.g., Stafford and Kline, 1996; Murray, 1997; Suter, 2004). These facts beg two questions, inspiring the current research: (1) Is this decision associated with marital duration? (2) Is this decision associated with the number of children of the marriage?

Murray (1997) observed that American men expressed the view that women retaining/hyphenating surname at marriage are less attractive and make worse mothers. As for women who hyphenate their surnames with those of their husbands, one study found that American undergraduates perceived them as relatively "career oriented" with men scoring high on the "Hostile Sexism Scale" (Glick and Fiske, 1996) rating them as relatively likely to violate sexual norms, including committing adultery (Stafford and Kline, 1996; but see Forbes et al., 2002) presumably, an act that can lead to divorce. In a study of married, Catholic, American women, any non-traditional marital surnaming practice was seen by some as indicating the intention to leave the marriage, or self-centeredness (Suter, 2004). A study of college students in the US found that women who retain surname at marriage were seen as less committed to the marriage (Robnett et al., 2016). Based on these results, there are beliefs of ties between (1) women's childbearing within marriage and activities or stances that may lead to divorce, with (2) marital surname change practice.

In the current study, wives who took their husbands' surnames are compared with wives who did not, to assess whether the former had more children and longer marriages. These putative predictors and outcomes are all available in divorce files and perhaps not, together, elsewhere. These predictors moreover comprise easily accessed demographic data: Should they show themselves predictive of marital duration, and/or number of children of the marriage, then (after validation) they could be used to predict such data. This, in turn, could help communities and professional caregivers better plan services, depending on whether these communities will on average need more housing for larger families and/or for new divorcé(e)s and their families, or whatever.

That an apparent sacrifice (of name) is being made in the long absence of legal force suggests that, perhaps, something is gained by brides doing it. To the extent it may "... mark women as to ownership ...," as alluded to by Wilson and Daly (1992, at p. 315), it may be done by the bride to please a husband who views her as his, and/or to fetter her own future ability to portray herself as not her husband's wife. To the extent the wife's new surname is used publicly, it may constitute a repeated, public declaration of the union and may be viewed by witnesses as a sign of commitment to the husband. Further evidence this may be the case is comprised of the facts that (1) any re-partnering of the (ex-)wife might be impaired, as the fact she has an (ex-)husband would be apparent every time her name (plus honorific) was spoken, and (2) any remarriage of hers might necessitate yet further, public action - to again change surname - that would come at additional costs.

If name change indexes a woman's marital commitment or is so construed, at least two hypotheses follow. That is, in addition to marital duration being predicted by the practice, women for whom the husband's investment in children would be particularly advantageous (e.g., women planning more children), may view surname change especially favorably.

Hypothesis 1: The marriages of opposite-sex couples in which the woman took the man's surname will be of greater duration.

Hypothesis 2: There will be a greater number of children produced within opposite-sex marriages in which the woman took the man's surname.

\section{MATERIALS AND METHODS}

\section{Characteristics of Geographical Area}

A sample of 2013-2014 divorce files on opposite-sex marriages from the Elgin County, Ontario, Canada, Superior Courthouse was searched. This courthouse houses all court files for all divorces within the county (chosen as the more accessible of the only two for which permission was granted for a search). Since the ability to search divorce files is limited, demographic characteristics of this county, along with the analogous data for Canada as a whole are provided in Table 1. This is so readers will be able to hypothesize whether results may apply in other jurisdictions given their demographic (dis)similarity. Unless otherwise noted, all data concerning Elgin County's residents and analogous data for Canada as a whole pertain to 2011; the nearest census year to 2013-2014. This study was exempt from ethical review.

Approximately 180 divorces are finalized in this county annually (personal communication: Melissa Kirby, Supervisor of Court Operations, Elgin County Courthouse, 8 September 2014). Elgin County spans $1,880.90$ square kilometers (total population of 87,461: Statistics Canada, 2012), and is comprised of a mid-sized city, a town, and six smaller townships and municipalities.

\section{Data Characteristics and Search Technique}

The searched divorce files tended to include the number and surnames of children, at least if these were minors. Each file included the first and surnames of the divorcing couple, their ages at marriage, and marriage duration (i.e., date of marriage to date of separation: full details available on request).

Each file also included the parties' Marriage Certificate, always indicating the premarital surname of the bride and groom. Given the files contained only information from the date of marriage, the criterion for each divorcing wife being deemed to have undergone marital surname hyphenation or retention was any mention in the court divorce file of her using her premarital surname hyphenated with that of her husband or alone, prior to the date of separation. Note that every page of the divorce file, except where it is noted as having been searched merely cursorily, below, was searched for such premarital or hyphenated name. Divorcing women who assumed (the norm in Ontario, Canada: MacEacheron, 2016a) 
TABLE 1 | Demographic data regarding Elgin County, Ontario, Canada, and Canada as a whole.

\begin{tabular}{|c|c|c|}
\hline Parameter & Elgin County & Canada as a whole \\
\hline $\begin{array}{l}\text { Married or Live with a } \\
\text { common-law partner }\end{array}$ & $44,185^{\mathrm{a}}(62 \%)$ & $16,084,490^{\mathrm{b}}(58 \%)$ \\
\hline $\begin{array}{l}\text { Married and Not } \\
\text { Separated }\end{array}$ & 38,035 (54\%) & $12,941,960$ (46\%) \\
\hline Separated & $2,230(3 \%)$ & $698,240(2 \%)$ \\
\hline Divorced & $3,750(5 \%)$ & $1,686,035(6 \%)$ \\
\hline Immigrant to Canada & $13 \%^{c}$ & $20 \%^{d}$ \\
\hline Unemployment & $9 \%{ }^{e}$ & $8 \%{ }^{f}$ \\
\hline $\begin{array}{l}\text { Average Yearly Individual } \\
\text { Income, } 2010 \text { (\$CDN) }\end{array}$ & $35,265^{\mathrm{g}}$ & $38,700^{h}$ \\
\hline $\begin{array}{l}\text { Median Yearly Individual } \\
\text { Income, } 2010 \text { (\$CDN) }\end{array}$ & $28,183^{g}$ & 29,859 \\
\hline $\begin{array}{l}\text { Average Yearly Household } \\
\text { Income, } 2010 \text { (\$CDN) }\end{array}$ & $69,158^{j}$ & $84,900^{k}$ \\
\hline $\begin{array}{l}\text { Median Yearly Household } \\
\text { Income, } 2010 \text { (\$CDN) }\end{array}$ & $60,175^{i}$ & $66,000^{k}$ \\
\hline $\begin{array}{l}\text { Percentage Households } \\
\text { Spending }>30 \% \\
\text { Combined Income on } \\
\text { Shelter }\end{array}$ & $24.2 \%$ & $25.2 \% \%^{m}$ \\
\hline
\end{tabular}

All data are for 2011 unless otherwise noted.

${ }^{a}$ Of a total population 15 years of age or over of 70,755 (Statistics Canada, 2011a).

${ }^{b}$ Of a total population 15 years of age or over of 27,869,345 (Statistics Canada, 2017).

${ }^{\circ}$ Of 85,870 residents of Elgin County residents providing data (Statistics Canada, 2013a).

${ }^{d}$ Of those providing data (Statistics Canada, 2011c,d).

${ }^{\circ}$ Of 69,205 residents 15 years of age or over providing data (Statistics Canada, 2011a).

${ }^{f}$ Of residents 15 years of age or over providing data (Newfoundland and Labrador

Statistics Agency, n.d.).

${ }^{9}$ Of 69,205 residents 15 years of age or over providing data (Statistics Canada, 2013a).

'nSource: The Canadian Press, 2013.

Source: Statistics Canada, 2011 d.

'Of 33,485 private households providing data (Statistics Canada, 2013a).

"Source: Canada Mortgage and Housing Corporation, n.d.

'Of 32,375 private households providing data (Statistics Canada, 2011b).

'mource: Statistics Canada, 2013b.

rather than legally changed surname at marriage, however, could have used their premarital surname within some pre-separation court file documents only. This may have been despite using a husband's surname at all other times prior to separation (see generally Friess, 2007; Snyder, 2009, for extremely low occurrence of opposite-sex marriage grooms' surname change).

The literature is nearly silent as to the proportion of women or men who take their spouse's surnames in same-sex marriages (but see Underwood and Robnett, 2019). Due to the concern there would be insufficient numbers of same-sex divorces to afford adequate statistical power for analyses, and due to the very limited search time available, only opposite-sex divorces were examined.

A large effect size was expected, based on large effect sizes being observed in previous, quantitative research concerning marital surname change (MacEacheron, 2011, 2020), the finding in previous qualitative work that marital surname choice is sometimes a fraught decision (Boxer and Gritsenko, 2005), and the author judging the consequences of women's marital surname choice to be high stakes. One such consequence is the surnaming of the children of the marriage solely for the father more often where the mother took the father's surname at marriage (Johnson and Scheuble, 2002; Duchesne, 2006) - something about which husbands have been anecdotally reported to care deeply (Cherlin, 1978).

Note that in the quantitative literature on women's marital surnaming, brides who kept their surname are usually grouped with those who hyphenated, and compared with those who took their husband's surname (without keeping their own, too: see review in MacEacheron, 2016a). The decision was taken to do so here, too, for two reasons. First, doing so would make results more easily interpretable alongside such literature. Second, doing so would help ensure adequate number of wives in each group to be compared, so that statistical tests' requirements would be met.

Two business days were granted to complete the current study's file search. Thus, a method for sampling the divorce files was devised. One such procedure would have consisted of searching divorce files for a single year or other period only, or some proportion $(1 / \mathrm{n})$ of these, with each $\mathrm{n}^{\text {th }}$ file chosen for review. The proportion (or number) chosen for searching, however, would have had to allow for searching at least $26 \times 2$ divorce files to allow for 0.8 statistical power in $t$-testing (with two groups) at alpha $=0.05$, with a large effect size, assuming each group contained at least 26 data points (Cohen, 1992). Assuming Johnson and Scheuble's (1995) US finding that $4.6 \%$ of wives in the said country currently retain or hyphenate their surname at marriage applied to couples divorcing in Elgin County however, the wife would be expected to have retained her premarital surname in only one out of 26 divorce files. To obtain 26 files in which the wife retained or hyphenated her premarital surname, approximately 565 files would thus need to be searched. This approach was not feasible given the time allowed.

As such, the number of files feasible to search in 1 day (all then-finalized 2014 divorces the files of which were not being used by court staff: 108) was cursorily pre-searched simply to ascertain in how many the wife had either retained or hyphenated surname (see Table 2). Adequate statistical power at expected, large effect size given the other statistical parameters used was achieved. That is so, as 26 of the 108 divorce files were of couples the wife of which had retained or hyphenated surname. As such, only the just-noted 108 were searched in detail. As many additional files $(n=59)$ as could be searched in the remaining time allowed were searched cursorily, in reverse chronological order by divorce finalization date. Thus, all files not being used by court staff during the search, with divorce finalization dates between June 12, 2014 and October 15, 2013 were completely or cursorily searched: a total of 167 files. (Note that five files were in use by court staff during the search). Searches were confined as much as possible in time, as the passage of time might make marriages and/or divorcing wives and/or divorcing husbands less comparable among themselves. Files searched (on September 11 and 12, 2014) were the most recent ones available.

Where children's birthdates were specified, only if such birthdates were on or following the date of marriage or if these children were specified as the children of both parties in other file documentation, were such children considered children of the marriage. Where children's birthdates were not 
TABLE 2 I Sample descriptive statistics: Out of total number of couples' divorce files searched ( $N=167)$, number providing data of each type.

Total

No. wives undergoing marital surname change

No. wives retaining surname

No. wives hyphenating surname

No. files searched in-depth

No. husbands changing/hyphenating surname

No. files with data on children (of marriage or not*)

No. citing 0 children

No. citing 1 child

No. citing 2 children

No. citing 3 children

No. citing 4 children

No. children not surnamed solely for husband

No. files with data on children of the marriage

No. citing 0 children

No. citing 1 child

No. citing 2 children

No. citing 3 children

No. citing 4 children

No. files with wife's income yearly data

Range $(\$ C D N)$

Average $\pm S D(\$ C D N)$

Median $(\$ C D N)$

No. files with husband's yearly income data

Range (\$CDN)

Average $\pm S D(\$ C D N)$

Median ( $\$ C D N$ )

No. files with wife's age ${ }^{* * * * *}$

As of date of marriage:

Range (years)

Average $\pm S D$ (years)

Median (years)

As of date of separation:

Range (years)

Average $\pm S D$ (years)

Median (years)

No. files with husband's age

As of date of marriage:

Range (years)

Average $\pm S D$ (years)

Median (years)

As of date of separation:

Range (years)

Average $\pm S D$ (years)

Median (years)

Average greater age of husbands (years $\pm S D$ )

Median greater age of husbands (years)

No. files with marital duration (date of marriage to separation)

Range (days)

Average $\pm S D$ (days)

Median (days)

Range (years)

Average $\pm S D$ (years)

Median (years)

No. wives previously divorced

No. previously changing surname

No. files searched cursorily
167

$126(75.45 \%)$

$38(22.75 \%)$

3 (1.80\%)

108

0

107

$34(31.78 \%)$

$26(24.30 \%)$

$34(31.78 \%)$

$10(9.34 \%)$

$3(2.80 \%)$

$1(0.74 \%)^{\text {**t }}$

108

37 (34.26\%)

24 (22.22\%)

34 (31.48\%)

$10(9.26 \%)$

$3(2.78 \%)$

42

$\$ 0.00-\$ 134,836.08$

$\$ 24,932.47 \pm \$ 33,530.22$

$\$ 11,057.86$

45

$\$ 0.00-\$ 305,273.12$

$\$ 63,737.13 \pm \$ 50,214.44$

$\$ 57,100.00$

108

19-50

$30.63 \pm 6.68$

28

$24-59$

$40.92 \pm 8.85$

41

108

$21-62$

$33.33 \pm 7.62$

32

$24-62$

$43.57 \pm 9.14$

42

$2.66 \pm 7.62$

2

108

$62-11,887$

$3,887.18 \pm 2,839.69$

3,121

<1-32

$10.14 \pm 7.79$

8

$16(9.60 \%)$

$8(4.80 \%)^{* * * * * * *}$

59

"Administrative error led to no datum being recorded as to whether there were any children who were not children of the marriage, for one couple. This couple had no children of the marriage (though each, separately, may have had other children - such as children born prior to the marriage). Only two children out of the total of 136 (1.47\%) mentioned in the divorce files were not children of the marriage being dissolved. One bore as his or her sole surname that of the relevant divorcing husband: No datum was ascertainable from the relevant file as to the surname of the other.

(Continued) 
** Only one child out of the total of 136 (0.74\%) did not bear solely the surname of the divorcing father. The divorcing woman (presumably, its mother) listing this child had retained her premarital surname. This child bore a hyphenated surname, combining his or her (presumed) mother's with that of the man she was divorcing from (presumably, the child's father).

${ }^{* * * *}$ Complete data were available as to couples' ages, for the portion of divorce files searched in-depth ( $\left.n=108\right)$. The separation date for one such marriage was not recorded due to administrative error. Thus, because marriage duration (i.e., time between separation date and wedding date) was used to assess age as of date of marriage, not only the duration of one marriage, but also spouses' age as of data of marriage, is missing for one divorcing couple (file).

${ }^{* * * *}$ Of the 16 divorce files the wives in which had previously divorced, data regarding previous marital change/retention/hyphenation was missing in three. Out of the 13 cases remaining, eight wives had changed surname previous to the marriage which was the subject of the divorce file (see above).

specified, it was assumed they were children of the marriage, due to these children's existence being relevant enough to the divorce proceedings to list them.

\section{Statistical Methods}

Planned analyses included $t$-test and two regressions, as follows. $t$-tests assessed whether marriages in which the wife took the husband's name were associated with younger bridal age and/ or longer duration. A regression analysis with number of children as dependent variable (DV) was conducted with the (effect-coded) predictor of whether the wife changed surname versus not (hyphenation included in the latter category), and control predictor of marriage length, to further test the hypothesis that marital surname change predicted number of children of these marriages. Marriage length was included as a covariate because it logically may, independently of whether or not the wife underwent marital surname change, predict number of children of the marriage, given that human conception and gestation require non-negligible amounts of time. In a second regression, length of marriage comprised the DV, the (effect coded) predictor was the ex-wife having undergone marital surname change or not, and bride's age served as co-variate (Given that wife's [or husband's] age at time of marriage might reasonably be related to ultimate marriage duration, and given that wife's age has been previously associated with her decision to change versus retain/hyphenate her surname at marriage, it was included as covariate.)

Divorce file data have a degree of reliability based on the fact they are publicly presented to the court which has the power to demand official records, by parties who are equal before the court (estranged husband and wife) with sometimes opposing interests as to what those data should be. These opposing interests stem from, for example, possessing either an interest in paying less or in receiving more child support funds. Each party has the right if not the obligation to present data on, for example, incomes, with the (disinterested) court reviewing them and coming up with income figures based in part or in whole on them (Government of Canada: Department of Justice, 2018).

\section{RESULTS}

\section{Descriptive Statistics}

A total of 167 divorce files were searched: $n=108$ in-depth, and $n=59$ cursorily.

In 33 divorces, the wives had either hyphenated or retained premarital surname, and in the remaining 75 , the wives had changed surname to that of their husbands. The proportion of children not receiving solely their father's surname did not differ depending on whether their mothers had taken their husbands' surnames $(t[17]=1.00, p=n s)$. (Note that this $t$-test must be considered underpowered: Cohen, 1992).

\section{Association Between Surname Retention Versus Change, and Number of Children}

Of the wives who had either retained their premarital surnames or hyphenated these with those of their husbands, average number of children of the marriage was $0.94( \pm 1.10)$. Of the remaining wives, average number of children of the marriage was $1.37( \pm 1.10)$.

Now reported is the planned regression with number of children of the marriage as DV, (effect-coded) predictor of wife undergoing surname change versus not (hyphenation included in the latter category), and covariate of marriage length, to test the hypothesis that marital surname change predicted number of children of these marriages. In an attempt to attain a good model fit, two different regressions appropriate to a DV of count data - Poisson and Negative Binomial -- were conducted. The two regressions' Akaike information criterion (AIC) and Bayesian information criterion (BIC) values were compared, to determine which regression achieved greater fit to the data. Lower AIC and BIC values in the Poisson $(\mathrm{AIC}=293.86, \mathrm{BIC}=326.71)$ than in the Negative Binomial modeling $(\mathrm{AIC}=301.88, \mathrm{BIC}=334.73$ ) showed better fit of the former. Thus, the former is reported (see Table 3 ).

The relevant value of exponentiated $b$ (incidence rate ratio) shows that every year of greater marriage duration is associated with a predicted 5\% increase in number of children of the marriage. Wife's surname choice was not significantly predictive.

\section{Association Between Surname Retention Versus Change, and Duration of Marriage}

Duration of marriage was not determinable for one divorce file in which it was searched, due to administrative error. Of the remaining ( $n=32$ ) marriages the wives in which had either hyphenated their premarital surname with that of their husbands or retained their premarital surname, average marriage duration was $2,639.00$ days $( \pm 2,353.04)$, or 6.78 years $( \pm 6.45)$. Of the marriages the wives in which had changed their surnames to those of their husbands $(n=75)$, average marriage duration was $4,419.73$ days $( \pm 2,875.82)$, or 11.57 years $( \pm 7.90)$. A $t$-test comparing duration of marriage between the former and latter demonstrated greater such duration in the former: $t$ $(105)=-3.09, p=0.002$, Cohen's $d=0.63$ or large. Note that as the relevant prediction was directional (i.e., that the 
TABLE 3 | Poisson regression, DV = number of children of the marriage $(n=107)$.

\begin{tabular}{|c|c|c|c|c|c|c|}
\hline Parameter & b & SE b & Wald & df & $p$ & $\operatorname{Exp}(b)$ \\
\hline Intercept & -0.40 & 0.20 & 3.84 & 1 & 0.05 & 0.67 \\
\hline Wife's surname choice - changed name & 0.10 & 0.21 & 0.22 & 1 & 0.641 & 1.10 \\
\hline Wife's surname choice - retained/hyphenated name & $0^{\mathrm{a}}$ & & & & & 1 \\
\hline Marriage duration (years) & 0.05 & 0.01 & 19.56 & 1 & 0.000 & 1.05 \\
\hline
\end{tabular}

${ }^{a}$ Set to 0 because it is a redundant parameter. In 30\% of marriages (effect coded 1), the wife had either retained her pre-marital surname or hyphenated it with that of her husband.

TABLE 4 | Negative binomial regression, DV = duration of marriage in years $(n=107)$.

\begin{tabular}{|c|c|c|c|c|c|c|}
\hline Parameter & b & SE b & Wald & df & $p$ & $\operatorname{Exp}(b)$ \\
\hline Intercept & 2.83 & 0.53 & 28.85 & 1 & 0.000 & 17.01 \\
\hline Wife's surname choice - changed name & 0.47 & 0.23 & 4.31 & 1 & 0.038 & 1.60 \\
\hline Wife's surname choice - retained/hyphenated name & $0^{\mathrm{a}}$ & & & & & 1 \\
\hline Wife's age at time of marriage & -0.03 & 0.02 & 3.62 & 1 & 0.057 & 0.97 \\
\hline
\end{tabular}

a Set to 0 because it is a redundant parameter. In 30\% of marriages (effect coded 1), the wife had either retained her pre-marital surname or hyphenated it with that of her husband.

former group's marriage duration would be less than that of the latter's), one-tailed testing was used.

Now discussed are the results of Poisson and Negative Binomial regressions with marriage duration in years as DV, (effect coded) predictor of wife undergoing surname change versus not (hyphenation included in the latter category), and covariate of wife's age at time of marriage. The two regressions' AIC and BIC values were compared, to determine which modeling achieved greater fit. Lower such values in the Negative Binomial $(\mathrm{AIC}=717.13, \mathrm{BIC}=725.15)$ than in the Poisson modeling $(\mathrm{AIC}=968.61, \mathrm{BIC}=976.63)$ showed better fit of the former. Thus, the former will be reported here (see Table 4).

Consistent with the relevant $t$-test result, the wife's surname choice was significantly predictive of marriage duration (Wald's $\left.\chi^{2}=4.31, d f=1, p=0.038\right)$, with having changed surname to that of the husband predicting greater such duration. As can be seen from the value of exponentiated b associated with wife's surname choice, women who changed surname had marriages of approximately $60 \%$ greater duration than women who retained their premarital surnames or hyphenated. Wife's age at time of marriage, on the other hand, was a marginally significant, negative predictor of marriage duration (Wald's $\left.\chi^{2}=3.62, d f=1, p=0.057\right)$.

\section{DISCUSSION}

A strong finding was that marriages in which women took their husbands' surnames lasted longer than marriages in which women did not. All else equal, given the greater number of years a married couple are together the more children are possible and reasonably expectable, number of years together should be an important predictor of number of children of marriages. Thus, to an extent, where women's marital surname choice predicts marital duration, such choice might, should this result prove generalizable, be used to help predict number of children of marriages.
Marital surname change did not predict, however, the number of children of the marriage, within a regression using that and marital duration as predictors. This could simply be due to the fact that marital duration is more predictive. Note that a planned $t$-test comparing the number of children of the married couples where the wife had kept or hyphenated her surname at marriage, versus those who had changed their surname to that of their husband, arguably showed a greater number of children for the latter: $t(106)=-1.90, p=0.03$, Cohen's $d=0.39$ or moderate (As my prediction was directional [i.e., that the former group of women would have fewer children of the marriage than would the latter], one-tailed testing was used). Note that this is merely an "arguable" finding, as without a large effect size, this analysis must be considered underpowered (Cohen, 1992). Women's marital surname choice, after any successful validation of its predictiveness of marital duration, might be used to predict communities' needs for divorce-relevant services (e.g., courtroom space, counseling), at the times these would tend to be needed. To the extent marital duration, again after any successful validation of its predictiveness, predicts number of children of marriages, the needs related to the number of children in a community (e.g., size of typical housing needed) may be better anticipated. As noted, the predictor of women's marital surname choice could comprise relatively easily accessed demographic data. This means it might easily be used as a predictor, as above.

It is speculated that a major piece of the puzzle of women's continued marital surname change, long past legal necessity and cultural novelty of retention/hyphenation, is that marriage may be understood as fundamentally a reproductive union (Buckle et al., 1966). It is this context in which children are raised, notwithstanding the tremendous historical and cross-cultural variability in the expectations and practices associated with marriage (Murdock, 1949). That women's marital surname change is done at the start of the bride and groom's reproductive union, may indicate that it pertains 
to that reproductive union. Previous social scientists studying women's marital surname choice have never done so under the lens of regarding marriage as a reproductive partnership. When marriage is viewed this way various, special hypotheses as to ultimate and proximal reasons for women's choice of marital surname arise. Women's marital surname change, as a public declaration of the union, may be construed as a signal of commitment by the bride to the groom. If this is true, it would follow that brides who particularly require investment by their future husband, for example because they intend on having more children, would regard women's marital surname change more positively and engage in it more.

Whether children born to opposite-sex parents bear their father's, mother's, or a combination surname affects the continuation of such names, and thus may be considered important. Here, the receipt by any child of a surname other than solely that of the presumed father, was a practice of negligible frequency. Women's marital surname change, given it is more frequently followed by children of the marriage being surnamed for the woman's husband (Johnson and Scheuble, 2002; Duchesne, 2006), would additionally signal intention to surname children of the marriage for the husband, and might constitute an attempt on the part of a bride to enhance paternal investment (see MacEacheron, 2016a). Desire for investment on the part of the wives, particularly, might be explicable by greater nutritional and other resourcing needs associated with pregnancy and lactation (e.g., Abdulla and Abdulla, 2004) and women's average income drops associated with childcare (see Cain Miller, 2014: note this may especially be true for women desiring a higher number of children), as well as by paternity uncertainty. Women might also particularly benefit from resource-investment because mothers, in multiple cultures, are the relatives providing the most care for children (e.g., in industrial societies, MingeKlevana, 1980). (Again, this may ultimately be due to paternity uncertainty, and thus a child's mother being its only certain, genetic parent.) Thus, mothers may tend to have less time than any other class of children's relatives, to procure resources for themselves and for their children, and yet may be responsible for direct provision of such resources to the latter.

The current male, romantic partner of a mother, as closest (along with her) putative, genetic relative of such child, is a strong candidate for investor in that child. That is so, since such investment augments the father's reproductive success albeit only if he is the genetic father. Women entering reproductive unions with men therefore, where it is particularly in those women's interest to elicit such support (e.g., if desiring more children), may attempt to provide more paternity assurance than other women. One way, again speculatively, would be to demonstrate commitment to him/the marriage, by undergoing the costly signal of marital surname change.

\section{Limitations}

The within method of determining whether a divorcing wife had either retained or hyphenated premarital surname likely entailed overestimation of the frequencies of these practices. No better estimation method seems devisable, however, given the absence of any other North American records of women's marital surname retention/hyphenation/change, which include all of bridal age, marriage duration, number of children, and children's surnames (see generally Cherlin, 1978; Goldin and Shim, 2004). Regardless, because some women who had changed surname at marriage were almost certainly erroneously included as retainers/hyphenators, predictions herein would tend to be less supported. Public records that cover all instances of a phenomenon (e.g., all divorces in a county), additionally, tend to possess ecological validity to the extent they are reliable - as divorce records may especially be, given the adversarial nature of presentation of data within, sometimes verified by disinterested courts (see generally Government of Canada: Department of Justice, 2018).

Divorcing spouses would seem to not be representative of spouses in general. It is reasonable to question whether data from those divorcing should be used to assess commitment (which, if unequivocal, would result in never divorcing). In other words, it may be that only spouses (including wives) with lesser marital commitment may be compared with one another via this study. Given, however, that a divorce is granted including where only one spouse wants it, and this spouse is at least sometimes the husband, divorcing wives could not solely represent wives with lesser marital commitment. $42.1 \%$ of marriages celebrated in 2008 in Ontario are projected to end in divorce within 30 years (Statistics Canada and Kelly, 2012). Given many marriages even of relatively long duration end in divorce, it is submitted that couples studied were not only representative of couples, or husbands or wives, of lesser marital commitment, at least at the inception of the marriage (when name change presumably mostly occurs). One implication of the presumed existence of at least some husband-initiated and/or mostly husband-driven divorce on the current data, when considering the finding that marriages the wife in which did not take the husband's surname did not last as long, is that husbands may be tending to drive or partially drive divorce, preferentially where their wives did not take their surnames.

Note the partial, basic explanation of women's marital surname change as a costly signal of commitment described in this article, is fully compatible with another explanation a reviewer suggested, which might predict the same outcomes found. That suggestion, was that people possessing traditional beliefs concerning gender and marriage, would tend to assortatively mate (and marry one another). This article seeks, however, to provide a more ultimate explanation than that assortative mating (on relevant beliefs) exists. Indeed, no hypothesis why assortative mating on traditional beliefs may exist has been, to the author's best knowledge, quantitatively tested in the literature on women's marital surname change, nor has the existence of such assortative mating even been empirically documented. It is even arguable that the fact that those with traditional beliefs concerning women's marital surname change and delaying or avoiding divorce may seek each other for marriage is not a potential explanation for 
women's marital surname change being associated with staying in marriages longer, but is instead a (potentially very valuable) observation that (1) these two beliefs tend to co-occur in individuals, and that (2) those with such beliefs tend to marry one another.

\section{Possible Future Directions}

The $24.55 \%$ share of divorcing wives in the within sample who did not change their surnames solely to that of their husbands appeared high compared with figures of 6 and 4.6\% of Johnson and Scheuble (1995) and Gooding and Kreider (2010), respectively, representative of US, married, non-divorcing women. On the other hand, the figure $24.55 \%$ appears similar to the analogous percentage of Canadian destination brides to Hawai'i in 2006 either keeping or hyphenating surname (25.22\%: MacEacheron, 2011). Assuming Canadian (or North American) representativeness of the current study's data, it is posited that (a) differences over time, and/or (b) cultural differences between Canada and the US (which might be assumed based on historical, geographical, and sometimes linguistic differences), might be partly explanatory. It is also possible that among the divorcing couples studied, marriages in which wives retained or hyphenated surname were oversampled disproportionately more marriages where women did not take their husbands' surnames ended in divorce in the given time period and area studied, compared with other such marriages. Current replication of the Johnson and Scheuble (1995) study in the US and Canada, would uncover whether (a) is operating. The possibility of (b) could be partially assessed via surveying the attitudes towards women's marital surname change, retention, and hyphenation, in both countries. To assess whether women's marital surname change remains as a strong predictor of marital duration among those going on to divorce where underlying culture differs from that of Canada, it may be useful to repeat the current study in countries in which women may change surname at marriage, but less commonly do.

It would seem possible to test whether marriages in Elgin County in which women did not take solely their husbands' surname were more likely to end in divorce than were other marriages within the time period studied. This could be accomplished by surveying women within Elgin County who were spouses in intact marriages within that period, as to whether they took (solely) their husbands' surname at marriage. Then, this rate of surname change versus retention/hyphenation would be compared with that of only the divorcing wives in the current study. Note, however, that there is no publicly available registry of women within intact marriages in Elgin County (or anywhere in Canada), nor even one just of women, to whom such a survey could be sent. Although there are directories of marriage certificates issued in Canada (e.g., in Ontario, administered by ServiceOntario), it is only possible to request a search for a marriage certificate of two given individuals married to each other (i.e., whose full names are provided: e.g., ServiceOntario, 2012-2016). Additionally, there seems to be no likely source of Elgin County's women's names, as such publicly available name listings as telephone directories may contain only a male householder's name or an initial.

\section{CONCLUSION}

After adequate replication, marital surname change versus retention/hyphenation might be used by demographers as one predictor of marital duration among those going on to divorce, and/or as a tool to help predict the number of children expected to be produced from such marriages. Such predictions could assist those planning the level of services to provide to (divorcing) spouses and their children. At least within the studied county and time period, the finding of greater marriage duration among opposite-sex (divorced) couples the wives in which took the husbands' names, is consistent with (1) marital surname change comprising one, possible signal of brides, regarding intention to remain in their marriages longer/under a greater set of circumstances, and/or divorce-relevant actions within the marriage, and/or (2) wives' marital surname choice impacting (i) which husbands married them, such that husbands with greater intention to remain in their marriages longer/under a greater set of circumstances married women indicating they would take the husbands' surnames, and/or (ii) husbands' divorce-relevant actions within the marriage.

\section{DATA AVAILABILITY STATEMENT}

The dataset presented in this article is not readily available, because divorcing parties' names must be presented in person at the divorce file repository, before these are provided for inspection. Requests to access the dataset should be directed to Maretta Miranda, Counsel, Ministry of the Attorney General (Ontario), Toronto, Canada.

\section{ETHICS STATEMENT}

Ethical review and approval was not required for the study on human participants in accordance with the local legislation and institutional requirements. Written informed consent for participation was not required for this study in accordance with national legislation and institutional requirements.

\section{AUTHOR CONTRIBUTIONS}

The author confirms being the sole contributor of this work and has approved it for publication.

\section{ACKNOWLEDGMENTS}

The author thanks to Maretta Miranda, Family Policy and Programs Branch, Court Services Division, Ministry of the Attorney General, and to Elgin County Court's Darcy Lampkin, Manager of Court Operations, and Melissa Kirby, Supervisor of Court Operations, for access to Elgin County divorce files. Note that most of this manuscript previously appeared in an online thesis (MacEacheron, 2016b). 


\section{REFERENCES}

Abdulla, C. D. A., and Abdulla, F. A. (2004). Exercise and pregnancy. Middle East J. Fam. Med. 2.

Boxer, D., and Gritsenko, E. (2005). Women and surnames across cultures: reconstituting identity in marriage. Wom. Lang. 28, 1-11.

Buckle, L., Gallup, G. G. Jr., and Rodd, Z. A. (1966). Marriage as a reproductive contract: patterns of marriage, divorce, and remarriage. Ethol. Sociobiol. 17, 363-377.

Cain Miller, C. (2014). The Motherhood Penalty vs. the Fatherhood Bonus. New York Times. Available at: https://www.nytimes.com/2014/09/07/upshot/ a-child-helps-your-career-if-youre-a-man.html (Accessed December 24, 2020).

Canada Mortgage and Housing Corporation (n.d.). "Household Incomes and Wealth." Government of Canada. Available at: https://www.cmhc-schl.gc.ca/ en/hoficlincl/homain/stda/data/data_012.cfm (Accessed May 17, 2018).

Cherlin, A. (1978). Hereditary hyphens? Psychol. Today 12:150.

Cohen, J. (1992). A power primer. Quant. Methods Psychol. 112, 155-159. doi: 10.1037/0033-2909.112.1.155

Duchesne, L. (2006). La situation démographique au Québec: Bilan 2006. Government of Quebec. Available at: www.stat.gouv.qc.ca/statistiques/ population-demographie/bilan2006.pdf (Accessed March 10, 2016).

Forbes, G. B., Adams-Curtis, L. E., White, K. B., and Hamm, N. R. (2002). Perceptions of married women and married men with hyphenated surnames. Sex Roles 46, 167-175.

Friess, S. (2007). More men taking wives last names. USA Today. [online] 20 March. Available at: http://www.usatoday.com/news/nation/2007-03-20-namesmarriage_N.htm (Accessed December 20, 2015).

Glick, P., and Fiske, S. T. (1996). The ambivalent sexism inventory: differentiating hostile and benevolent sexism. J. Pers. Soc. Psychol. 70, 491-512.

Goldin, C., and Shim, M. (2004). Making a name: women's surnames at marriage and beyond. J. Econ. Perspect. 18, 143-160. doi: 10.1257/0895330041371268

Gooding, G. E., and Kreider, R. M. (2010). Women's marital naming choices in a nationally representative sample. J. Fam. Issues 31, 681-701. doi: 10.1177/0192513X09344688

Government of Canada: Department of Justice (2018). Fact Sheet - Income Disclosure for Child Support Purposes. Available at: https://www.justice. gc.ca/eng/fl-df/fact2-fiches2.html (Accessed August 21, 2019).

Johnson, D. R., and Scheuble, L. K. (1995). Women's marital naming in two generations: a national study. J. Marriage Fam. 57, 724-732. doi: 10.2307/353926

Johnson, D. R., and Scheuble, L. K. (2002). What should we call our kids? Choosing children's surnames when parents' last names differ. Soc. Sci. J. 39, 419-429. doi: 10.1016/S0362-3319(02)00203-3

Lockwood, P., Burton, C., and Boersma, K. (2011). Tampering with tradition: rationales concerning women's married names and children's surnames. Sex Roles 65, 827-839. doi: 10.1007/s11199-011-0034-1

MacEacheron, M. (2011). Hawaii data: women's marital surname change by bride's age and jurisdiction of residence. Names 59, 4-11. doi: 10.1179/00277731 0X12759861710501

MacEacheron, M. (2016a). North American women's marital surname change: practices, law, and patrilineal descent reckoning. Evol. Psychol. Sci. 2, 149-161. doi: 10.1007/s40806-016-0045-9

MacEacheron, M. (2016b). Novel predictors of women's surname retention at marriage. Electronic Thesis and Dissertation Repository. 4534. Available at: https://ir.lib.uwo.ca/etd/4534

MacEacheron, M. (2020). Women's marital surname change by bride's age and jurisdiction of residence: a replication. Names 68, 193-209. doi: 10.1080/00277738.2020.1751442

Minge-Klevana, W. (1980). Does labour time increase with industrialization? A survey of time allocation studies. Curr. Anthropol. 2, 279-298.

Murdock, G. P. (1949). Social Structure. New York: Macmillan Co.

Murray, T. E. (1997). Attitudes toward married women's surnames: evidence from the American Midwest. Names 45, 163-183. doi: 10.1179/nam.1997.45.3.163

Nesse, R. M. (2001). Evolution and the Capacity for Commitment. New York: Russell Sage Foundation.

Newfoundland and Labrador Statistics Agency (n.d.). Annual Average Unemployment Rate: Canada and Provinces 1976-2017, Department of Finance. Available at: www.stats.gov.nl.ca/statistics/labour/pdf/unemprate.pdf (Accessed May 17, 2018).
Robnett, R. D., and Leaper, C. (2013). “Girls don't Propose! Ew.”: a mixedmethods examination of marriage tradition preferences and benevolent sexism in emerging adults. J. Adolesc. Res. 28, 96-121. doi: 10.1177/0743558412447871

Robnett, R. D., Underwood, C. R., Nelson, P. A., and Anderson, K. J. (2016). "She might be afraid of commitment": perceptions of women who retain their surname after marriage. Sex Roles 75, 500-513. doi: 10.1007/ s11199-016-0634-x

Scheuble, L., and Johnson, D. R. (1998). Attitudes toward women's marital name choices. Names 46, 83-96. doi: 10.1179/nam.1998.46.2.83

ServiceOntario (2012-2016). How to get a copy of an Ontario marriage certificate online. Available at: https://www.ontario.ca/page/how-get-copy-ontariomarriage-certificate-online (Accessed January 13, 2016).

Snyder, K. (2009). All names are not equal: Choice of marital surname and equal protection. Wash. U.J.L. \& Pol'y, 30, 561-587.

Stafford, L., and Kline, S. L. (1996). Women's surnames and titles: Men's and women's views. Commun. Res. Rep. 13, 214-224. doi: 10.1080/08824099609362089

Statistics Canada (2011a). National Household Survey, Statistics Canada Catalogue no. 99-012-X2011047. Available at: http://www12.statcan.gc.ca/nhs-enm/2011/ dp-pd/dt-td/Rp-eng.cfm?LANG=E\&APATH=5\&DETAIL $=0 \& D I M=0 \& F L=A \&$ $\mathrm{FREE}=0 \& \mathrm{GC}=3534 \& \mathrm{GID}=0 \& \mathrm{GK}=2 \& \mathrm{GRP}=0 \& \mathrm{PID}=105929 \& \mathrm{PRID}=0 \& \mathrm{PTYP}$ $\mathrm{E}=105277 \& \mathrm{~S}=0 \& \mathrm{SHOWALL}=0 \& \mathrm{SUB}=0 \&$ Temporal $=2013 \& \mathrm{THEME}=96 \& \mathrm{VID}=$ $0 \& V N A M E E=\& V N A M E F=($ Accessed November 25,2015$)$.

Statistics Canada (2011b). National Household Survey, Statistics Canada Catalogue no. 99-012-X2011051. Available at: http://www12.statcan.gc.ca/nhs-enm/2011/ dp-pd/dt-td/Rp-eng.cfm?LANG=E\&APATH=5\&DETAIL $=0 \& D I M=0 \& F L=A \&$ FREE $=0 \& \mathrm{GC}=3534 \& \mathrm{GID}=0 \& \mathrm{GK}=2 \& \mathrm{GRP}=0 \& \mathrm{PID}=106327 \& \mathrm{PRID}=0 \& \mathrm{PTYP}$ $\mathrm{E}=105277 \& \mathrm{~S}=0 \& \mathrm{SHOWAL}=0 \& \mathrm{SUB}=0$ \&Temporal $=2013 \& \mathrm{THEME}=96 \& \mathrm{VID}=$ $0 \& V N A M E E=\& V N A M E F=($ Accessed November 25, 2015).

Statistics Canada (2011c). The Canadian Population in 2011. Ministry of Industry. Available at: www12.statcan.ca/census-recensement/2011/as-sa/ 98-310-x/98-310-x2011001-eng.cfm (Accessed May 17, 2018).

Statistics Canada (2011d). National Household Survey: Data Tables. Ministry of Industry. Available at: www12.statcan.gc.ca/nhs-enm/2011/dp-pd/dt-td/ Rp-eng.cfm ? TABID $=2 \& \mathrm{LANG}=\mathrm{E} \& \mathrm{APATH}=3 \& \mathrm{DETAIL}=0 \& \mathrm{DIM}=0 \& \mathrm{FL}=\mathrm{A} \&$ FREE $=0 \& \mathrm{GC}=0 \& \mathrm{GK}=0 \& \mathrm{GRP}=0 \mathrm{PID}=105411 \& \mathrm{PRID}=0 \& \mathrm{PTYPE}=105277 \& \mathrm{~S}=$ 0\&SHOWALL $=0 \&$ SUB $=0 \&$ Temporal $=2013 \&$ THEME $=95 \&$ VID $=0 \&$ VNAMEE $=\& V N A M E F=($ Accessed May 17, 2018).

Statistics Canada (2012). Elgin, Ontario (Code 3534) and Manitoba (Code 46) (table). Census Profile. 2011 Census. Statistics Canada Catalogue no. 98-316XWE. Ottawa. Released 24 October 2012. Available at: http://www12.statcan. gc.ca/census-recensement/2011/dp-pd/prof/index.cfm?Lang=E (Accessed November 25, 2015).

Statistics Canada (2013a). Elgin, CTY, Ontario (Code 3534) (table). National Household Survey (NHS) Profile. 2011 National Household Survey. Statistics Canada Catalogue no. 99-004-XWE. Ottawa. Released 11 September 2013. Available at: http://www12.statcan.gc.ca/nhs-enm/2011/dp-pd/prof/index. cfm?Lang=E (Accessed November 25, 2015).

Statistics Canada (2013b). Homeownership and Shelter Costs in Canada. Ministry of Industry. Available at: www12.statcan.gc.ca/nhs-enm/2011/as-sa/99-014x2011002-eng.pdf (Accessed May 17, 2018).

Statistics Canada (2017). 2011 Census of Population. Minister of Finance. Available at: www12.statcan.gc.ca/census-recensement/2011/dp-pd/tbt-tt/Rpeng.cfm ? LANG $=\mathrm{E} \& A P A T H=3 \& D E T A I L=0 \& D I M=0 \& F L=A \& F R E E=0 \& G C=0$ $\& \mathrm{GID}=0 \& \mathrm{GK}=0 \& \mathrm{GRP}=1 \& \mathrm{PID}=103832 \& \mathrm{PRID}=10 \& \mathrm{PTYPE}=101955 \& \mathrm{~S}=0 \& \mathrm{~S}$ HOWALL $=0 \& S U B=0 \&$ Temporal $=2011 \&$ THEME $=89 \& \mathrm{VID}=0 \& \mathrm{VNAMEE}=\&$ $\mathrm{VNAMEF}=($ Accessed May 17, 2018).

Statistics Canada, and Kelly, M. B. (2012). Divorce Cases in Civil Court, 2010/2011. Available at: http://www.statcan.gc.ca/pub/85-002-x/20122001/ article/11634-eng.htm (Accessed August 7, 2014).

Suter, E. A. (2004). Tradition never goes out of style: the role of tradition in women's naming practices. Commun. Rev. 7, 57-87. doi: 10.1080/10714420490280198

The Canadian Press (2013). "Wealthiest 1\% earn 10 times more than average Canadian.” CBC. Available at: www.cbc.ca/news/business/wealthiest-1-earn-10times-more-than-average-canadian-1.1703017 (Accessed May 17, 2018).

Underwood, C. R., and Robnett, R. D. (2019). "I would like us to share a name so that we can be recognized in society." marital surname preferences in same-sex relationships. J. Homosex. 68, 290-310. doi: 10.1080/ 00918369.2019 .1651110 
Wilson, M., and Daly, M. (1992). "The man who mistook his wife for a chattel," in The Adapted Mind: Evolutionary Psychology and the Generation of Culture. eds. J. H. Barkow, L. Cosmides and J. Tooby (Oxford University Press), 289-322.

Conflict of Interest: The author declares that the research was conducted in the absence of any commercial or financial relationships that could be construed as a potential conflict of interest.
Copyright (c) 2021 MacEacheron. This is an open-access article distributed under the terms of the Creative Commons Attribution License (CC BY). The use, distribution or reproduction in other forums is permitted, provided the original author(s) and the copyright owner(s) are credited and that the original publication in this journal is cited, in accordance with accepted academic practice. No use, distribution or reproduction is permitted which does not comply with these terms. 